\title{
Peningkatan Kualitas Pembelajaran Daring Guru dengan Produk Multimedia Interaktif di SMA Daarut Tauhiid Boarding School
}

\author{
Improving the Quality of Teacher Online Learning \\ with Interactive Multimedia Products at Daarut Tauhiid Boarding School
}

\author{
Riky Taufik Afif \\ Universitas Telkom, Bandung, Jawa Barat, Indonesia \\ rtaufikafif@telkomuniversity.ac.id
}

Naskah diterima tanggal 20/08/2021, direvisi akhir tanggal 24/08/2021, disetujui tanggal 30/08/2021

\begin{abstract}
Abstrak
Pada sektor pendidikan di Indonesia wabah COVID-19 membuat proses belajar mengajar menjadi daring (dalam jaringan). Pada situasi tersebut para guru dituntut lebih kreatif untuk menjaga situasi kondusif selama pembelajaran daring. Menjadi tantangan tersendiri karena situasi yang biasanya lebih fleksibel selama pertemuan tatap muka menjadi berubah karena tidak lagi bertemu secara fisik antara pengajar dan siswa. Pembelajaran berbasis Multimedia interaktif bisa menjadi salah satu pilihan agar pembelajaran bisa lebih menarik dalam rangka memudahkan para siswa memahami materi pembelajaran. Tujuan penelitian ini adalah melakukan peningkatan kualitas pembelajaran dari di SMA Daarut Tauhiid Boarding School melalui produk multimedia interaktif sebagai media pembelajarannya. Teknik analisis data yang digunakan pada penelitian ini adalah metode penelitian camuran kualitatif dan kuantitatif atau mix methods untuk dapat mengolah data dan menyimpulkan hasil penelitian dengan baik. Populasi penelitian ini adalah siswa kelas XII IPA dan IPS dengan jumlah sampel 160 siswa kelas XII putra. Penelitian ini menawarkan solusi dalam rangka menambah wawasan guru terhadap penggunaan Multimedia berbasis ICT untuk pembelajaran dan semakin memantapkan kemampuan guru dalam memaksimalkan media interaktif bagi yang sudah terbiasa menggunakannya. Hasil dari penelitian ini adalah menganalisis sekaligus meningkatkan kemampuan guru dalam membuat media pembelajaran berbentuk media interaktif multimedia animasi. Ditemukan bahwa dengan multimedia interaktif siswa putra SMA Daarut Tauhiid Boarding School sebanyak 94,5\% merasa sangat terbantu dalam memahami materi dan antusias selama mengikuti pembelajaran daring.
\end{abstract}

Kata Kunci: Animasi, Daring, Media Pembelajaran, Multimedia.

\begin{abstract}
The education sector in Indonesia the COVID-19 outbreak makes the teaching and learning process online (online). In this situation, teachers are required to be more creative to maintain conducive situations during online learning. It becomes a challenge because situations that are usually more flexible during face-to-face meetings become changed because they no longer meet physically between teachers and students. Interactive multimedia-based learning can be one of the options so that learning can be more interesting in order to make it easier for students to understand learning materials. The purpose of this research is to improve the quality of learning from Daarut Tauhiid Boarding School high school through interactive multimedia products as a learning medium. The data analysis techniques used in this study are camuran research methods or mix methods. Qualitative narrative analysis and quantitative descriptive statistics to be able to process data and conclude research results well. The population of this study is students of class XII IPA and IPS with a sample number of 160 students of class XII men. This research offers solutions in order to add teacher insights to the use of ICT-based Multimedia for learning and further strengthen the ability of teachers to maximize interactive media for those who are accustomed to using it. The result of this study is to analyze and improve the ability of teachers in making learning media in the form of interactive multimedia animation media. It was found that with interactive multimedia high school students Daarut Tauhiid Boarding School as much as $94.5 \%$ felt very helped in understanding the material and enthusiastic during online learning.
\end{abstract}

Keywords: Animation, Learning Media, Multimedia, Online.

How to cite (APA Style) : Afif, R T. (2021). Peningkatan Kualitas Pembelajaran Daring Guru dengan Produk Multimedia Interaktif di SMA Daarut Tauhiid Boarding School. Jurnal Penelitian Pendidikan, 21 (2), 2021. 25-35. doi: https://doi.org/10.17509/jpp.v21i2.37871

e-ISSN: 2541-4135 I p-ISSN: 1412-565 X

Copyright $(\subset$ authors, 2021 


\section{PENDAHULUAN}

Wabah pandemi global COVID-19 (Corona Virus Disease 2019) memberikan dampak pada setiap elemen kehidupan masyarakat di Indonesia. Tidak hanya di negara besar dan kota besar namun sampai pelosok dan perkampungan juga mendapat dampak negatif dari meluasnya penyebaran COVID-19. Sektor-sektor yang terdampak COVID-19 bukan hanya sektor ekonomi tapi juga sektor pendidikan. Situasi dunia pendidikan ditengah pandemi COVID-19 ini mengalami perubahan khususnya pada segi situasi proses belajar mengajar (PBM) yang pada umumnya dilaksanakan secara tatap muka menjadi daring (dalam jaringan) atau online. Belajar dapat diartikan sebagai proses perubahan tingkah laku melalui interaksi antara individu dengan lingkungannya (Hamalik, O., 1990) baik itu proses pembelajaran daring (dalam jaringan) maupun luring (luar jaringan). Situasi ini tentunya menjadi tantangan tersendiri bagi para praktisi dunia pendidikan khususnya para Guru yang harus menyiapkan materi pembelajaran sebaik dan sekreatif mungkin agar kondusitifitas pembelajaran tetap terjaga meski tidak ada pertemuan tatap muka. Perlu disadari bahwa pembelajaran itu merupakan suatu system, yang di dalamnya terdapat sejumlah komponen yang saling berhubungan satu sama lainnya dalam rangka mencapai tujuan. Beberapa komponen dimaksud meliputi: (1) tujuan, (2) bahan/materi ajar, (3) metoda, (4) alat/media dan, (5) evaluasi (Ali, M., 2008).

Para Guru khususnya di SMA Daarut Tauhiid Boarding School mayoritas sudah bisa dan biasa mengakses internet untuk menunjang pembelajaran. Namun, dengan situasi pembelajaran daring jarak jauh seperti sekarang para guru juga dituntut untuk tetap menjaga kualitas pembelajaran agar tetap baik dan menarik. Evaluasi selama 3 bulan kebelakang pelaksanaan pembelajaran daring dirasakan adanya kejenuhan karena penyampaian materi bersifat monoton dengan media pengantar yang dirasa biasa dan kurang menarik. Dalam penelitian ini penulis melakukan pendampingan dan melakukan analisis dari hasil pendampingan kepada para guru SMA Daarut Tauhiid Boarding School agar mampu menyajikan sebuah media pembelajaran dalam bentuk multimedia interaktif yang baik dan menarik guna membantu tercapainya tujuan-tujuan pembelajaran yang diharapkan. Kelebihan yang dimiliki oleh produk atau media pembelajaran multimedia interaktif menurut Timothy, J. N et al., (2000), antara lain: (1) memberikan pembelajaran dengan penyimpanan informasi yang baik; (2) desain pembelajaran yang ditunjukan bagi siswa dengan karakteristik belajar yang berbeda; (3) langsung ditujukan bagi domain pembelajaran efektif tertentu; (4) menghadirkan pembelajaran yang realistis; (5) dapat meningkatkan motivasi peserta didik; (6) menuntut siswa agar lebih interaktif; (7) kegiatan pembelajaran lebih bersifat individual; (8) memiliki konsistensi materi yang diberikan; dan (9) siswa mempunyai pengendalian terhadap kecepatan belajar setiap individu.

Potensi pembuatan media pembelajaran interaktif dalam menunjang terlaksananya pembelajaran dengan baik dan tercapainya tujuan-tujuan pembelajaran sangat besar. menurut Adam, S. (2015) bahwa media pembelajaran adalah segala sesuatu baik berupa fisik maupun teknis dalam proses pembelajaran yang dapat membantu guru untuk mempermudah dalam menyampaikan materi pelajaran kepada siswa sehingga memudahkan pencapaian tujuan pembelajaran yang telah dirumuskan.

Dengan media pembelajaran berbasis multimedia interaktif peluang untuk terselenggaranya pembelajaran yang menarik, efektif dan efisien sangat mungkin dicapai. Media sebagai salah satu komponen dalam sistem itu, mempunyai fungsi sebagai sarana komunikasi non-verbal. Sebagai salah satu komponen sistem, berarti media mutlak harus ada atau harus dimanfaatkan di dalam setiap pembelajaran (Supriyono, 2018). Selain itu multimedia interaktif juga memudahkan guru dalam mengelola materi pembelajaran. Ditengah sedang maraknya pembelajaran jarak jauh dengan media daring maka penggunaan media pembelajaran berbasis pada multimedia interaktif menjadi sangat membantu dan membuka peluang besar untuk tercapainya tujuan-tujuan pembelajaran. Selain 
membantu guru dalam pelaksanaan pembelajaran jarak jauh dan daring, media pembelajaran berbasis pada multimedia interaktif juga dapat memancing kreatifitas siswa.

Ditengah wabah pandemi COVID-19 muncul berbagai masalah yang juga berdampak pada sektor pendidikan seperti yang telah diuraikan diatas. Berbagai macam solusi dirumuskan untuk menyelesaikan permasalahn baru maupun yang bersifat klasik dalam proses pelaksanaan pendidikan. SMA Daarut Tauhiid Boarding School sesuai dengan Visi dan Misinya memiliki tekad untuk peka terhadap perubahan dan inovasi dan senantiasa beradaptasi secara cepat dengan berbagai macam keadaan yang ada khususnya pada situasi wabah COVID-19 ini.

Permasalahn terkait dengan menurunnya kualitas pembelajaran karena situasi hari ini menuntut pembelajaran dilaksanakan secara jarak jauh dan bersifat daring dapat diatasi dengan meningkatkan kreativitas guru dalam menyusun dan menyajikan materi pembelajaran. Media pembelajaran berbasis pada karya multimedia interaktif dapat menjadi solusi dari masalah diatas dan meningkatkan kreativitas guru maupun para siswa. Umumnya, otak akan lebih mudah dan lama menyimpan ingatan yang tersimpan di otak kanan berupa inputan informasi dengan pengantar gambar, musik, warna dan mediamedia bergerak.

Diharapkan dengan penyajian berbasis multimedia interaktif pembelajaran menjadi lebih menarik dan para siswa pun lebih antusias dan mudah menerima informasi dan ilmu yang disampaikan guru. Juga bagi para guru dapat memudahkan pelaksanaan pembelajaran, meningkatkan skill media pembelajaran berbasis ICT dan dapat menjaga kondusifitas pembelajaran di kelas virtual. Karena media interaktif memungkinkan ada partisipasi dua arah antara siswa dan guru. Carpenter dan Dale dalam Darma, I.M., (1983) menyatakan bahwa belajar memerlukan partisipasi dan latihan. Belajar pada dasarnya melakukan aktivitas, maka dalam proses pembelajaran para siswa perlu banyak berpartisipasi. Partisipasi siswa dapat dilakukan dengan jalan mendengarkan, melihat, menulis, merasakan, dan memikirkan. Hal ini sejalan dengan yang dikatakan Rusyan A.T., (1993) yakni pada prinsipnya media itu dipakai dalam proses pembelajaran dengan maksud untuk membuat cara berkomunikasi yang lebih efektif dan efisien.

Media pembelajaran berbasis pada multimedia interaktif juga dapat meningkatkan kepekaan guru dan siswa atau siapapun yang terlibat dengan proses pendidikan bahwa peran inovasi ICT melalui media seni rupa dan desain tidak dapat teralakan lagi. Perubahan pasti ada dan para guru perlu terus meningkatkan kualitas penguasaan media berbasis ICT ini kedepan. Meningkatkan jam terbang mereka dengan media digital dan jangan sampai gaptek (gagap teknologi) dalam sebuah produk kreativitas. Karena guru harus selalu menjadi insan pembelajar dan peka terhadap inovasi. Apabila guru berhenti belajar maka sulit untuk mengajar. Berhubung ilmu yang diajarkan media yang disajikan akan terus berlomba dengan percepatan zaman. Media pembelajaran berbasis multimedia interaktif ini dapat diterapkan pada setiap mata pelajaran baik itu praktik maupun teori.

\section{METODE PENELITIAN}

Pada penelitian ini penulis menggunakan metode penelitian campuran atau mix methods. Penelitian campuran atau mix methods adalah bahwa, metode penelitian kombinasi (mixed methods) adalah suatu metode penelitian yang mengkombinasikan atau menggabungkan antara metode kuantitatif dan metode kualitatif untuk digunakan secara bersama-sama dalam suatu kegiatan penelitian sehingga diperoleh data yang lebih komprehensif, valid, reliabel dan objektif (Sugiyono, 2011:404). Metode penelitian campuran digunakan untuk dapat mengolah dan menghasilkan data hasil penelitian dengan baik dan komprehensif sehingga dapat disimpulkan sebuah hasil penelitian yang tepat dan akurat. Populasi penelitian ini adalah siswa putra kelas XII IPA dan IPS dari SMA Daarut Tauhiid Boarding School dengan jumlah sampel 160 siswa dari kelas IPA dan IPS. 
Teknik analisisnya menggunakan teknik analisis kualitatif yang menggambarkan situasi kondisi dan hasil dari pembelajaran daring yang dilaksanakan di SMA Daarut Tauhiid Boarding School, juga ditambah dengan analisis deskriptif dari data statistik hasil uji media pembelajaran multimedia interaktif. Adapun subjek penelitiannya adalah seluruhnya siswa putra kelas XII sebanyak 160 orang di SMA Daarut Tauhiid Boarding School.

\section{HASIL DAN PEMBAHASAN}

Tahapan awal penelitian, penulis melakukan pendampingan berupa pelaksanaan kegiatan Seminar dan Workshop. Seminar tentang studi kreativitas dan design strategy dalam proses belajar mengajar khususya dalam proses pembelajaran juga tentang pengetahun seputar produk multimedia dan kontribusinya untuk peningkatan sebuah proses pembelajaran. Asupan pengetahuan tentang studi kreativitas sangat penting mengingat ini menjadi mindset guru dalam membuat media pembelajaran nantinya.

Kemudian diselenggarakan workshop pembuatan media pembelajaran berbasis pada produk multimedia interaktif untuk para guru seluruh mata pelajaran di SMA Daarut Tauhiid Boarding School. Juga ada pemberian hibah aset ilustrasi dan media pendukung untuk menciptakan media interaktif bagi guru.

Persiapan dilakukan dengan melakukan survey kepada objek penelitian yaitu para guru tentang kebutuhan yang diperlukan terkait dengan permasalah proses pendidikan ditengah wabah COVID-19. Kemudian dirumuskan solusi untuk masalah yang dihadapi dengan membentuk kegiatan. Adapun klasifikasi bentuk persiapannya adalah sebagai berikut:

1. Observasi permasalahan kontemporer di setiap sektor yaitu ekonomi, sosial, pendidikan.

2. Ditentukan permasalahan pada sektor pendidikan akibat imbas pandemi COVID-19.

3. SMA Daarut Tauhiid Boading School sebagai sekolah full day berbasis pesantren memiliki masalah keterampilan guru seputar memaksimalkan produk ICT untuk pembelajaran daring/ jarak jauh.

4. Menawarkan solusi karya multimedia interaktif untuk membantu guru selama WFH dalam mengajar dan meningkatkan partisipasi siswa selama $S F H$.

Sebelum mengukur efektivitas hasil produk multimedia interaktif pada pembelajaran daring, para guru diberikan pendampingan dalam pembuatan produk multimedia interaktif yang dapat diterapkan pada pembelajaran daring selama pandemi COVID-19. Pendampingan yang diberikan adalah pendampingan dalam bentuk seminar multimedia kreatif dan workshop pembuatan produk multimedia animasi. Para peserta yang terdiri dari guru-guru SMA Daarut Tauhiid Boarding School sangat antusias dan mengikuti pendampingan ini dari awal sampai akhir.

Kegiatan pendampingan dilaksanakan secara daring (dalam jaringan) karena masih diberlakukannya Work From Home (WFH) bagi para guru di lingkungan SMA Daarut Tauhiid Boarding School. Sehingga seluruh rangkaian kegiatan pendampingan dilaksanakan secara daring sampai tahap evaluasi kegiatan. Proses Pelaksanaan Penelitian disajikan pada gambar berikut: 


\section{INPUT}

1. SMA berbasis Boarding School dibawah naungan Yayasan Pendidikan Daarut Tauhiid

2. Pemberdayaan melalui pelatihan multimedia pembelajaran untuk peningkatan kualitas pembelajaran daring

\section{DUKUNGAN}

1. Yayasan Daarut Tauhiid Bandung.

2. Yayasan Pendidikan Daarut Tauhiid Bandung

3. SMA Daarut Tauhiid Bandung
METODE DAN BENTUK KEGLATAN

Workshop produk aplikatif.

Dilaksanakan secara daring

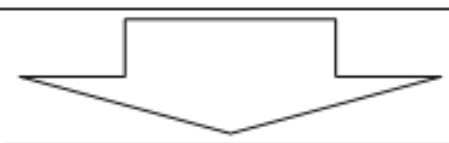

EVALUASI DAN OUTPUT

Guru membuat produk multimedia interaktif yang aplikatif pada pembelajaran daring.
Urgensi dan solusi serta luaran yang ditawarkan

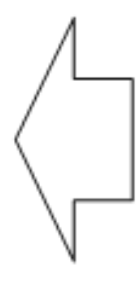

1. Memberikan pengetahuan dan keterampilan seputar multimedia pembelajaran.

2. Workshop berupa produk aplikatif. Teknologi tepat guna.

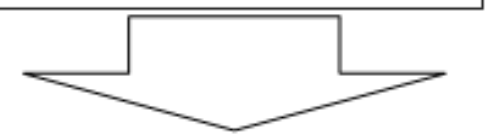

METODE PELAKSANAAN

\section{DUKUNGAN}

1. Pendanaan internal Telkom University.

2. Partisipasi 27 guru SMADT

3. Dosen Tel-U berlatar belakang kompetensi multimedia desain

Gambar 1. Proses Pelaksanaan Penelitian (sumber: pribadi, 2021)

Para guru membuat media pembelajaran interaktif berbasis produk multimedia dengan efek animasi yang dapat diterapkan pada pembelajaran daring selama pandemi. Multimedia adalah penggunaan beberapa media untuk menyajikan informasi. Kombinasi ini dapat berisi teks, grafik, animasi, gambar, video, dan suara. Teknologi saat ini, bagaimanapun memungkinkan pendidik dan siswa untuk mengintegrasikan, menggabungkan dan berinteraksi dengan media yang jauh melampaui apa yang sebelumnya (Nopriyanti, 2015). 


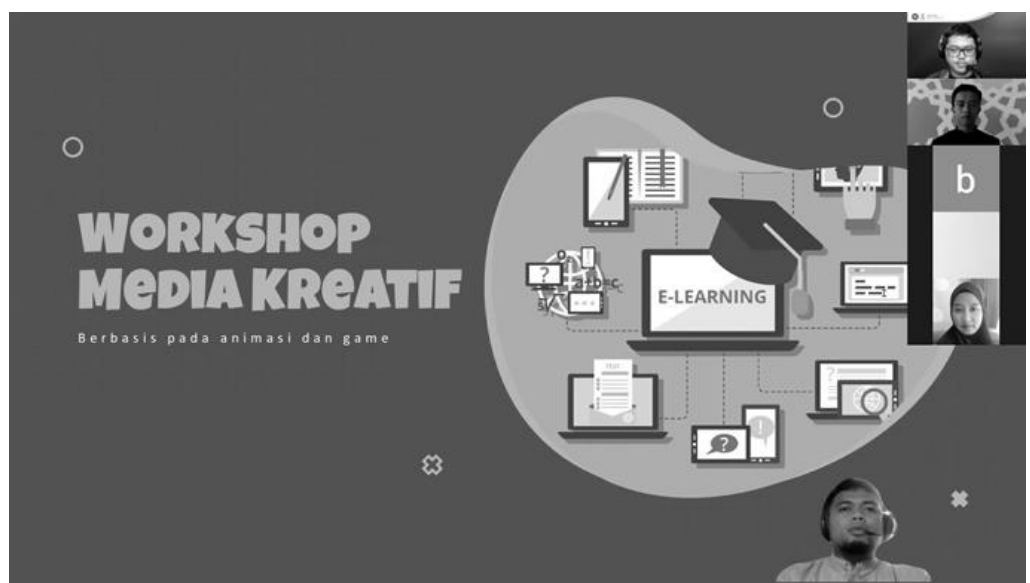

Gambar 2. Workshop pembuatan Produk Multimedia Interaktif (sumber: pribadi, 2021)

Produk multimedia interaktif yang disusun mengacu pada produk animasi yang memaksimalkan informasi melalui gambar bergerak. Produk multimedia interaktif ini digunakan oleh para guru untuk menyajikan materi pembelajaran yang disajikan melalui learning management system (LMS) untuk para siswa di SMA Daarut Tauhiid Boarding School.

Dalam proses perancangan media pembelajaran multimedia interaktif ini menggunakan teknologi software komputer. Menurut Rahmayanti (2015) bahwa teknologi pembelajaran terus mengalami perkembangan seiring dengan perkembangan zaman. Software komputer yang digunakan untuk membuat produk multimedia interaktif ini adalah menggunakan Microsoft Power Point 2016 dan Adobe Flash Professional. Perpaduan dua software yang familiar dan mudah didapatkan ini relatif sederhana tetapi hasilnya sangat baik diterapkan dalam proses pembelajaran selama pembelajaran daring di SMA Daarut Tauhiid Boarding School.

Produk multimedia yang berhasil dibuat oleh para guru SMA Daarut Tauhiid Boarding School adalah whiteboard animation, sebuah animasi interaktif yang menggantikan fungsi papan tulis dikelas selama pembelajaran daring. Whiteboard animation ini dapat dipakai oleh guru dan siswa ketika mencoba menulis sesuatu cukup dengan mengetikan teks di keyboard masing-masing dengan terlebih dahulu menekan whiteboardnya.

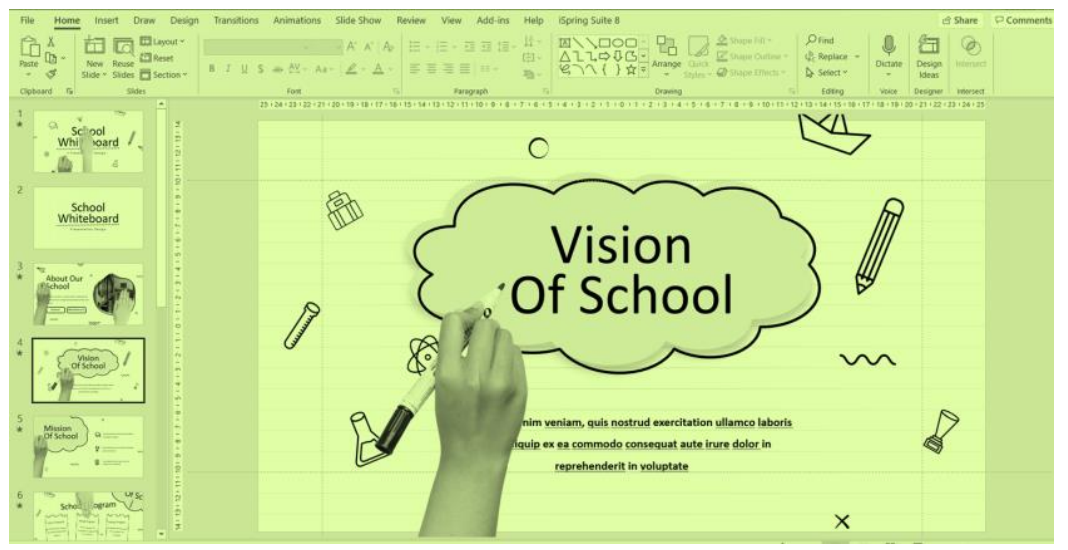

Gambar 3. Whiteboard animation yang dibuat dengan Microsoft Power Point 2016 (sumber: pribadi, 2021) 
Produk selanjutnya yang dibuat adalah game edukasi yang berisi materi pembelajaran sesuai Rencana Pelaksanaan Pembelajaran (RPP) mata pelajaran yang diampu oleh masing-masing guru. Game edukasi ini berisi materi yang akan disampaikan pada pelaksanaan pembelajaran dengan menyajikannya melalului game dan efek animasi. Para siswa bisa memilih jawabanya sendiri ketika ada pertanyaan muncul dari sesi materi.

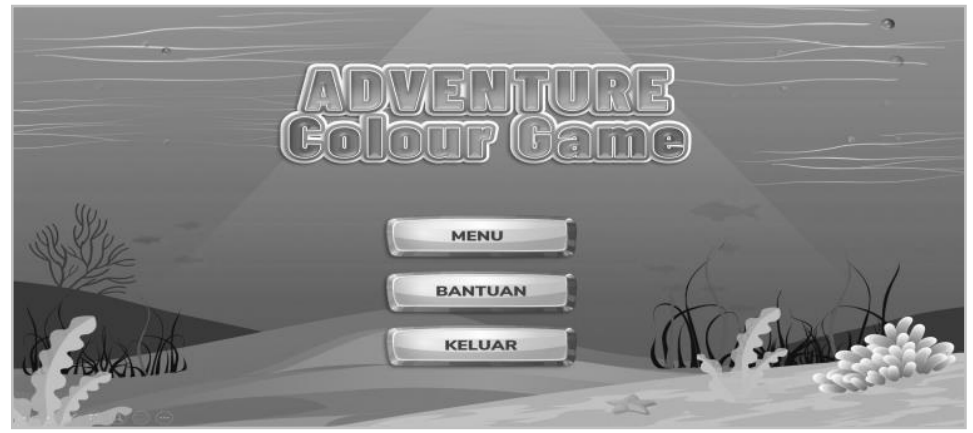

Gambar 4. Game Edukasi Pembelajaran (sumber: pribadi, 2021)

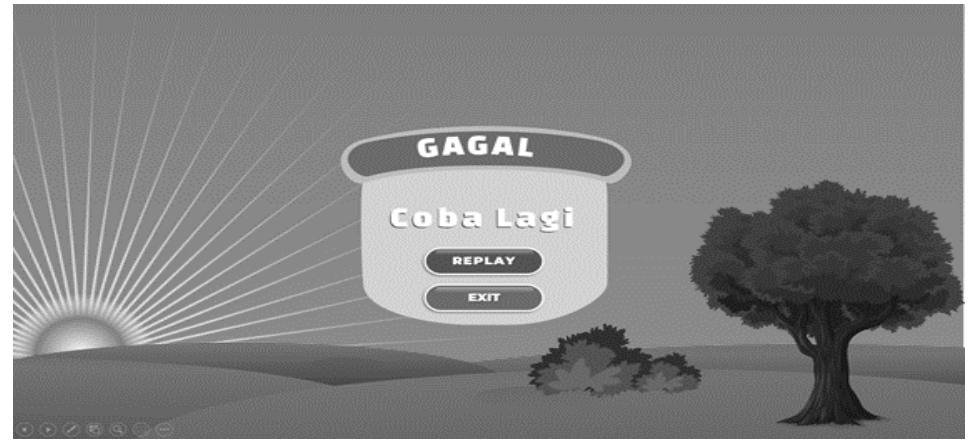

Gambar 5. Game Edukasi Pembelajaran (sumber: pribadi, 2021)

\section{Hasil}

Game edukasi menyajikan materi dengan efek animasi dan simulai materi pembelajaran melalui game interaktif yang juga ditampilkan dengan efek animasi agar menarik dan interaktif selama pembelajaran berlangsung. Dari hasil pengujian produk multimedia interaktif pada empat mata pelajaran yaitu Bahasa Indonesia, Bahasa Inggris, Sejarah dan Seni Budaya diserbarkan kuisioner pada para siswa tentang user experience (pengalaman pengguna) dalam menggunakan produk multimedia interaktif ini. Hasilnya sebanyak $94,5 \%$ merasa terbantu (sangat setuju) dan tertarik semangat belajarnya selama pembelajaran daring dengan produk multimedia ini. Sisa 5,5\% merasa biasa-biasa saja (setuju) dan 0\% tidak terbantu sama sekali.

Pada mata pelajaran Bahasa Indonesia, media pembelajaran multimedia interaktif berbasis animasi sangat bisa meningkatkan suasana dan kualitas pembelajaran daring dengan total presentasi sangat setuju sebesar $88 \%$ dan sisanya $12 \%$ setuju untuk kategori tidak setuju $0 \%$. Hasil maksimal dapat dilihat pada media pembelajaran multimedia interaktif dapat membantu siswa memahami materi pembelajaran dan menginginkan media pembelajaran multimedia interaktif dipertahankan dengan presentase $100 \%$ responden memilih sangat setuju. Kesimpulan dari pengujian media pembelajaran multimedia interaktif berbasis animasi pada mata pelajaran Bahasa Indonesia adalah sangat baik karena presentasi sangat puas/sangat setuju berada pada presentase $88 \%$. Hasil kuisioner efektifitas multimedia interaktif Mata Pelajaran Bahaa Indonesia dapat dilihat pada tabel 1. 
Tabel 1. Hasil kuisioner efektifitas multimedia interaktif Mata Pelajaran Bahaa Indoneia

Mata Pelajaran: Bahasa Indonesia

Kelas : XII IPS 2

Guru: Taopik Rahman, S.Pd.

\begin{tabular}{|c|c|c|c|c|c|c|c|}
\hline Penilaian Kriteria & $\begin{array}{c}\text { Sangat } \\
\text { tidak } \\
\text { setuju }\end{array}$ & $\begin{array}{c}\text { Tidak } \\
\text { setuju }\end{array}$ & setuju & $\begin{array}{c}\text { Sangat } \\
\text { setuju }\end{array}$ & Total & $\begin{array}{c}\text { Total } \\
\text { sangat } \\
\text { setuju }\end{array}$ & $\begin{array}{c}\text { Total } \\
\text { setuju } \\
(\%)\end{array}$ \\
\hline
\end{tabular}

1. Media pembelajaran membantu memahami materi dengan lebih baik

\section{(1)}

$$
0
$$

0

2. Media pembelajaran menarik dan memotivasi suasana selama pembelajaran

3. Media pembelajaran menghilangkan bosan

4. Media pembelajaran membantu menghilangkan kejenuhan selama belajar dirumah

5. Menginginkan media pembelajaran animasi interaktif ini dipertahankan.

\begin{tabular}{ccccccc}
0 & 0 & 8 & 32 & 40 & $80 \%$ & $20 \%$ \\
0 & 0 & 8 & 32 & 40 & $80 \%$ & $20 \%$ \\
0 & 0 & 8 & 32 & 40 & $80 \%$ & $20 \%$ \\
0 & 0 & 0 & 40 & 40 & $100 \%$ & $0 \%$ \\
\hline
\end{tabular}

Untuk mata pelajaran Bahasa Inggris, media pembelajaran multimedia interaktif berbasis animasi ini juga didapat hasil yang sangat memuaskan dengan seluruh responden merasa sangat setuju/sangat puas pada semua kategori dari mulai poin multimedia interaktif ini dapat membantu siswa memahami materi pelajaran sampai para responden menginginkan media pembelajaran multimedia interaktif ini dipertahankan untuk pembelajaran daring. Presentase keseluruhannya adalah $100 \%$ sangat puas/sangat setuju dengan kesimpulan media pembelajaran multimedia interaktif dapat meningkatkan kualitas pembelajaran Bahasa Inggris selama pembelajaran daring dimasa pandemi. Hasil kuisioner efektifitas multimedia interaktif Mata Pelajaran Bahaa Inggris dapat dilihat pada tabel 2.

Tabel 2. Hasil kuisioner efektifitas multimedia interaktif Mata Pelajaran Bahasa Inggris

Mata Pelajaran: Bahasa Inggris

Kelas : XII IPA 1

Guru: Japar Sidik, S.Pd.

\section{Penilaian Kriteria}

$\begin{array}{cccc}\text { Sangat } & \text { Tidak } & \text { setuju } \\ \text { tidak } & \text { setuju } & \\ \text { setuju } & & \end{array}$

$\begin{array}{cccc}\begin{array}{c}\text { Sangat } \\ \text { setuju }\end{array} & \text { Total } & \begin{array}{c}\text { Total } \\ \text { sangat } \\ \text { setuju } \\ (\%)\end{array} & \begin{array}{c}\text { Total } \\ \text { setuju } \\ (\%)\end{array} \\ & & & \end{array}$

1. Media pembelajaran membantu memahami materi dengan lebih baik

2. Media pembelajaran menarik dan memotivasi suasana selama pembelajaran

3. Media pembelajaran menghilangkan bosan

4. Media pembelajaran membantu menghilangkan kejenuhan selama belajar dirumah

5. Menginginkan media pembelajaran animasi interaktif ini dipertahankan.

$$
\text { Jumlah }
$$

\begin{tabular}{lllllll}
0 & 0 & 0 & 40 & 40 & $100 \%$ & $0 \%$ \\
0 & 0 & 0 & 40 & 40 & $100 \%$ & $0 \%$ \\
0 & 0 & 0 & 40 & 40 & $100 \%$ & $0 \%$ \\
0 & 0 & 0 & 40 & 40 & $100 \%$ & $0 \%$ \\
0 & 0 & 0 & 40 & 40 & $100 \%$ & $0 \%$ \\
\hline
\end{tabular}

Pada mata pelajaran Sejarah presentasenya juga sangat baik dengan total $90 \%$ merasa sangat setuju/sangat puas dengan media pembelajaran multimedia interaktif dengan rincian pada poin kategori media pembelajaran ini menarik dan memotivasi suasana pembelajaran dan media pembelajaran ini menghilangkan bosan juga pada poin kategori media pembelajaran ini perlu dipertahankan seluruh 
responden menyatakan sangat setuju/sangat puas dengan total presentase sebesar 100\%. Sedangkan pada poin kategori media pembelajaran ini membantu mereka memahami materi pelajaran dan menghilangkan kejenuhan sebesar 75\%. Secara keseluruhan sangat baik dengan total presentasi kepuasan adalah 90\%. Hasil kuisioner efektifitas multimedia interaktif Mata Pelajaran Sejarah dapat dilihat pada tabel 3 .

Tabel 3. Hasil kuisioner efektifitas multimedia interaktif Mata Pelajaran Sejarah

\begin{tabular}{|c|c|c|c|c|c|c|c|}
\hline Mata Pelajaran: Sejarah & & & & & & & \\
\hline Kelas : XII IPS 3 & & & & & & & \\
\hline Guru: Rendy Azhar,S.Pd. & & & & & & & \\
\hline Penilaian Kriteria & $\begin{array}{c}\text { Sangat } \\
\text { tidak } \\
\text { setuju }\end{array}$ & $\begin{array}{l}\text { Tidak } \\
\text { setuju }\end{array}$ & setuju & $\begin{array}{l}\text { Sangat } \\
\text { setuju }\end{array}$ & Total & $\begin{array}{c}\text { Total } \\
\text { sangat } \\
\text { setuju } \\
(\%)\end{array}$ & $\begin{array}{c}\text { Total } \\
\text { setuju } \\
(\%)\end{array}$ \\
\hline $\begin{array}{l}\text { Media pembelajaran membantu memahami materi } \\
\text { dengan lebih baik }\end{array}$ & 0 & 0 & 10 & 30 & 40 & $75 \%$ & $25 \%$ \\
\hline $\begin{array}{l}\text { Media pembelajaran menarik dan memotivasi } \\
\text { suasana selama pembelajaran }\end{array}$ & 0 & 0 & 0 & 40 & 40 & $100 \%$ & $0 \%$ \\
\hline Media pembelajaran menghilangkan bosan & 0 & 0 & 0 & 40 & 40 & $100 \%$ & $0 \%$ \\
\hline $\begin{array}{l}\text { Media pembelajaran membantu menghilangkan } \\
\text { kejenuhan selama belajar dirumah }\end{array}$ & 0 & 0 & 10 & 30 & 40 & $75 \%$ & $25 \%$ \\
\hline $\begin{array}{l}\text { Menginginkan media pembelajaran animasi } \\
\text { interaktif ini dipertahankan. }\end{array}$ & 0 & 0 & 0 & 40 & 40 & $100 \%$ & $0 \%$ \\
\hline Jumlah & & & & & & $90 \%$ & $10 \%$ \\
\hline
\end{tabular}

Terakhir pada mata pelajaran Seni Budaya juga seperti pada mata pelajaran Bahasa Inggris dimana total sangat puas/sangat setuju mencapai angka maksimal yaitu 100\%. Seluruh responden setuju bahwa media pembelajaran multimedia interaktif berbasis animasi ini sangat membantu mereka dalam proses pembelajaran seni budaya yang hasilnya tersaji pada tabel 4.

Tabel 4. Hasil kuisioner efektifitas multimedia interaktif Mata Pelajaran Seni Budaya

\section{Mata Pelajaran: Seni Budaya}

Kelas : XII IPA 2

Guru: Regina Sudana, S.Pd.

\section{Penilaian Kriteria}

\begin{tabular}{|c|c|c|c|c|c|c|}
\hline $\begin{array}{c}\text { Sangat } \\
\text { tidak } \\
\text { setuju }\end{array}$ & $\begin{array}{c}\text { Tidak } \\
\text { setuju }\end{array}$ & setuju & $\begin{array}{c}\text { Sangat } \\
\text { setuju }\end{array}$ & Total & $\begin{array}{c}\text { Total } \\
\text { sangat } \\
\text { setuju } \\
(\%)\end{array}$ & $\begin{array}{c}\text { Total } \\
\text { setuju } \\
(\%)\end{array}$ \\
\hline
\end{tabular}

1. Media pembelajaran membantu memahami materi dengan lebih baik

2. Media pembelajaran menarik dan memotivasi suasana selama pembelajaran

3. Media pembelajaran menghilangkan bosan

4. Media pembelajaran membantu menghilangkan kejenuhan selama belajar dirumah

5. Menginginkan media pembelajaran animasi interaktif ini dipertahankan.

Jumlah

\begin{tabular}{lllllll}
0 & 0 & 0 & 40 & 40 & $100 \%$ & $0 \%$ \\
0 & 0 & 0 & 40 & 40 & $100 \%$ & $0 \%$ \\
0 & 0 & 0 & 40 & 40 & $100 \%$ & $0 \%$ \\
0 & 0 & 0 & 40 & 40 & $100 \%$ & $0 \%$ \\
0 & 0 & 0 & 40 & 40 & $100 \%$ & $0 \%$ \\
\hline
\end{tabular}




\section{Pembahasan}

Dari hasil pemaparan diatas dapat disampaikan bahwa media pembelajaran dengan produk multimedia interaktif dapat meningkatkan kualitas pembelajaran daring yang dekat dengan kesan membosankan, jenuh dan menyulitkan siswa memahami materi pembelajaran. Produk multimedia dapat meningkatkan tingkat pemahaman siswa terhadap materi pembelajaran yang disampaikan oleh guru mata pelajaran. Tercermin lewat hasil presentase keseluruhan dari semua mata pelajaran yang mencapai 94,5\% dari mata pelajaran Bahasa Indonesia, Bahasa Inggris, Sejarah dan Seni Budaya adalah sangat puas/sangat setuju. Rinciannya pada mata pelajaran Seni Budaya dan Bahasa Inggris nilai presentasenya mencapai $100 \%$, Bahasa Indonesia sebesar $88 \%$, Sejarah $90 \%$.

Apabila dianalisis hasil ini maka pada mata pelajaran seni yang memang mengangkat materi pelajaran seputar budaya visual maka ini cocok dan hasilnya pun maksimal $100 \%$. Kemudian pada mata pelajaran Bahasa Inggris yang terbantu pemahaman bahasa asing lewat sajian informasi grafis dalam media pembelajaran multimedia interaktif maka hasilnya pun maksimal $100 \%$. Sedangkan pada mata pelajaran Bahasa Indonesia dan sejarah yang banyak materinya tersaji lewat dongeng, narasi cerita dan tekstual hasilnya tidak maksimal 100\% tetapi masih pada kategori tinggi dengan $88 \%$ dan $90 \%$.

Namun hasil keseluruhan tinggi karena pada dasarnya media pembelajaran multimedia interaktif ini menarik dan secara aplikatif dapat diterapkan pada semua mata pelajaran. Tujuannya adalah untuk mencapai tujuan dari pembelajaran mata pelajaran itu sendiri dimana peserta didik atau para siswa dituntut untuk aktif berperan dalam pembalajaran (interaktif) tidak hanya bersumber pada guru saja, seperti yang diungkapkan Hamalik, O., (2002) pembelajaran dikatakan berhasil dan berkualitas apabila seluruhnya atau setidak tidaknya sebagian besar peserta didik terlibat secara aktif, baik fisik, mental maupun sosial dalam proses pembelajaran.

\section{KESIMPULAN}

Paparan yang telah penulis sampaikan diatas hasil dari analisis dan pengaruh implementasi media pembelajaran multimedia interaktif, maka dapat diambil kesimpulan bahwa produk multimedia interaktif sebagai media pembelajaran dapat meningkatkan kualitas pembelajaran daring selama pandemi COVID-19. Multimedia interaktif yang dibuat berfokus pada animasi yang diterapkan pada learning management system (LMS) di SMA Daarut Tauhiid Boarding School. Peningkatan yang dirasakan para siswa tergambarkan melalui hasil kuisioner kepuasan mahasiswa terhadap produk multimedia interaktif dari empat mata pelajaran yaitu Bahasa Indonesia, Bahasa Inggris, Sejarah dan Seni Budaya yang mencapai $94,5 \%$ sangat puas dan merasa terbantu dengan produk multimedia interaktif yang diimplementasikan dalam pembelajaran daring selama pandemi COVID-19. Kesimpulan ini senada dengan yang disampaikan Tafonao T., (2018) Peranan media pembelajaran dalam proses belajar dan mengajar merupakan satu kesatuan yang tidak dapat dipisahkan dari dunia pendidikan. Media pembelajaran merupakan segala sesuatu yang dapat digunakan untuk menyalurkan pesan pengirim kepada penerima, sehingga dapat merangsang pikiran, perasaan, perhatian, dan minat peserta didik untuk belajar. Kesimpulan hasil penelitian ini juga diperkuat dari argumen hasil penelitian dari Computer Technology Research (CTR) menunjukkan bahwa seorang hanya dapat mengingat apa yang dilihatnya sebesar 20\%, 30\% dari yang didengarnya, 50\% dari yang didengar dan dilihatnya, dan $80 \%$ dari yang didengar, dilihat, dan dikerjakannya secara simultan. Hal ini bearti bahwa penggunaan media seperti, multimedia interaktif memungkinkan siswa untuk meraih hasil belajar $80 \%$ dari yang dipelajarinya. (Suyanto, 2003). 


\section{DAFTAR PUSTAKA}

Adam, S. (2015). Pemanfaatan media pembelajaran berbasis teknologi informasi bagi siswa kelas X SMA Ananda Batam. Computer Based Information System Journal, 3(2).

Ali, M., (2008). Guru dalam Proses Belajar-Mengajar. Penerbit Sinar Baru :Bandung.

Darma, I. M., (1983). Alat Peraga dan Komunikasi Pendidikan, Diktat Materi Pelajaran Alat Peraga dan Komunikasi Pendidikan, untuk Siswa SPG Negeri Denpasar.

Hamalik, O., (1990). Media Pendidikan. Penerbit Alumni : Bandung.

Hamalik, O., (2002). Psikologi Belajar Mengajar. Bandung: Sinar Baru Algessindo

Timothy, J. N., Donald, A. S., James, D. L., \& James, D. R. (2000). Instructional technology for teaching and learning. New Jersey: Prentice-Hall Inc.

Nopriyanti, (2015). Pengembangan Multimedia Pembelajaran Interaktif Kompetensi Dasar Pemasangan Sistem Penerangan dan Wiring Kelistrikan di SMK. Jurnal Pendidikan Vokasi. 5(2). 222-235.

Rahmayanti, (2015). Penggunaan Media IT Dalam Pembelajaran. Dalam Jurnal Ilmiah CIRCUIT Vol. 1 No. 1 Juli: 92.

Rusyan A. T., (1993). Proses Belajar Mengajar yang Efektif Tingkat Pendidikan Dasar. Penerbit : Bina Budaya : Bandung.

Sugiyono. (2011). Metode Penelitian Kuantitatif, Kualitatif dan R\&D. Bandung: Afabeta.

Supriyono. (2018). Pentingnya Media Pembelajaran untuk Meningkatkan Minat Belajar Siswa SD. Jurnal Pendidikan Dasar. 2(1):43-48.

Suyanto, M. (2003). Multimedia: alat untuk meningkatkan keunggulan bersaing. Yogyakarta: percetakan Andi.

Tafonao, T., (2018). Peranan Media Pembelajaran Dalam Meningkatkan Minat Belajar Mahasiswa. Jurnal Komunikasi Pendidikan. 2(2): 103-114. 